\title{
Behavioural and biochemical alterations by chlorpyrifos in aquatic insects: an emerging environmental concern for pristine Alpine habitats
}

\author{
Valeria Di Nica $^{1} \cdot$ Ana Belén Muñiz González ${ }^{2,3} \cdot$ Valeria Lencioni $^{2}$ (D) Sara Villa ${ }^{1}$ \\ Received: 20 June 2019 / Accepted: 9 September 2019 \\ (C) Springer-Verlag GmbH Germany, part of Springer Nature 2019
}

\begin{abstract}
This study aimed to assess how different concentrations of the insecticide chlorpyrifos $(1.1,5.24,11,52.4,110,262,524$ and $1100 \mathrm{ng} \mathrm{L}^{-1}$ ) affect the swimming behaviour of Diamesa zernyi larvae following exposure. A video tracking system was employed to analyse two swimming traits (total distance moved and average speed) of the larvae simultaneously after 3 days of exposure to the pesticide at $2{ }^{\circ} \mathrm{C}$. The behavioural results were also interpreted according to biochemical responses to oxidative stress (OS) induced by chlorpyrifos, based on malondialdehyde (MDA) and protein carbonyl (PCC) content. Both distance and speed significantly decreased after $72 \mathrm{~h}$ of exposure to chlorpyrifos concentrations of $\geq 110 \mathrm{ng} \mathrm{L}{ }^{-1}$, under which significant OS was detected as lipid peroxidation (level of MDA) and protein carbonylation (level of carbonyl). Analysis of altered swimming behaviour, along with MDA and carbonyl content, indicated that $\geq 110 \mathrm{ng} \mathrm{L}^{-1}$ contamination levels of the insecticide cause the organism to reallocate energy normally used for locomotor activity to repair cell damage, which might explain the strong impairment to locomotor performance. Locomotor performance is an ecologically relevant trait for elucidating the population dynamics of key species, with disturbance to this trait having long-term negative impacts on population and community structure. Therefore, chlorpyrifos insecticides represent a serious ecological risk for mountain aquatic species based on the detrimental effects observed in the current study, as the tested concentrations were those at which the insecticide is found in many Alpine rivers of Italy.
\end{abstract}

Keywords Pesticides $\cdot$ Chironomids $\cdot$ Diamesa zernyi $\cdot$ Locomotion ability $\cdot$ Oxidative stress response $\cdot$ Alpine glacier-fed streams

Responsible editor: Giovanni Benelli

Electronic supplementary material The online version of this article (https://doi.org/10.1007/s11356-019-06467-2) contains supplementary material, which is available to authorized users.

Valeria Lencioni

valeria.lencioni@muse.it

1 Department of Earth and Environmental Sciences - DISAT, University of Milano - Bicocca, Milan, Italy

2 Department of Invertebrate Zoology and Hydrobiology, MUSE-Museo delle Scienze, Corso del Lavoro e della Scienza, 3, 38122 Trento, Italy

3 Group of Biology and Environmental Toxicology, Department Physics, Mathematics and Fluids, Science Faculty, National Distance Education University (UNED), Madrid, Spain

\section{Introduction}

Fauna living in pristine areas, such as glacial streams at high altitude in the Alps, is exposed to seasonal contamination by chlorpyrifos (CPF) and other currently used pesticides transported by the atmosphere at median-long distances (Santolaria et al. 2015; Ferrario et al. 2017; Guida et al. 2018; Rizzi et al. 2019). As pesticides are designed to affect biota, there may also be some deleterious effects on non-target organisms living in the aquatic environment where these substances are found (Liu and Schelar 2012; Stehle and Schulz 2015). The presence of pesticides in freshwater ecosystems could impair aquatic fauna, affecting different levels of complexity (including direct acute and chronic effects, bioaccumulation and enrichment in food chains), and might alter the equilibrium of biological communities. Aquatic contamination by pesticides and their effects on wildlife are one of the most studied problems of environmental concern (Darko et al. 2008; Liu et al. 
2016; Sun et al. 2018). The presence of pesticides at high altitudes is considered an emerging environmental problem about which limited information is available (Lencioni 2018; Lencioni et al. 2018; Villa et al. 2018a). In fact, the concentrations detected in Italian glacial fed streams have been found to induce unacceptable effects in high-altitude freshwater ecosystems (Rizzi et al. 2019).

However, knowledge remains limited on how these contaminants affect aquatic fauna, with studies almost exclusively focusing on chironomids of the genus Diamesa (Diptera, Chironomidae) (Lencioni 2018). Villa et al. (2018a) demonstrated the inhibitory effect of chlorpyrifos (CPF) on the swimming behaviour of Diamesa zernyi larvae, which is a key species of the macrobenthic community in cold streams (Lencioni and Rossaro 2005). Significant changes to mobility were observed in larvae exposed to an environmentally relevant concentration (1100 ng L $\mathrm{n}^{-1}$ ) of CPF after $72 \mathrm{~h}$. Several recent studies have demonstrated that, after exposure to sub-lethal concentrations of contaminants, aquatic organisms survive successfully but could undergo significant behavioural changes (such as escaping to avoid contamination, changing eating habits or the mode of locomotion) (Gerhardt 2007; Amiard-Triquet 2009; Hellou 2011). Behavioural disturbance of key species might also impact ecosystem maintenance (Saaristo et al. 2018). In fact, the detrimental effects of low contamination on the behaviour of key species could extend to the community level, by altering natural competitive and/or prey/predator interactions among species (Gerhardt 2007; Amiard-Triquet 2009; Hellou 2011). In turn, subsequent changes to community composition could cause shifts in nutrient cycling, which might impact ecosystem equilibriums (Saaristo et al. 2018).

Changes to behaviour involve an integrated whole-organism response that often incorporates early stress signals produced at the sub-organismal level, including changes to biochemical, cellular and/or physiological levels. Changes to the suborganismal level could induce some compensatory mechanisms to exposed organisms, such as increased energy consumption and/or a reduced energy uptake (Duquesne 2006), which might, ultimately, affect the fitness of the population (Amiard-Triquet 2009). For instance, at low exposure to pollutants, some antioxidant and detoxifying enzymes are activated by the organism in an attempt to repair damaged cells. These actions could lead to the reallocation of energy necessary for other functions, such as locomotor behaviour. Also, reactive oxygen species (ROS) causing oxidative stress (OS) could be rapidly produced under conditions of environmental disturbance (Betteridge 2000). The rapidity with which ROS are produced means that these responses could be used as "early warning" signals of ongoing stress (Amiard-Triquet 2009).

However, these biomarkers alone cannot provide information about how higher levels of hierarchical organisation are impacted (i.e. populations and communities), which are more relevant for the proper ecological risk assessment of chemicals in aquatic environments (Forbes et al. 2006). Thus, behavioural responses provide a measurable link between the effects observed at sub-organismal and supra-organismal levels (Dell'Omo 2002). Furthermore, because of the earliness and sensitivity with which behavioural responses can be provided (in comparison with standard acute and chronic toxicity tests), they might represent a more useful and sensitive tool to improve analyses of the ecological effects of environmental contamination (Scott and Sloman 2004; Sloman and Mcneil 2012; Saaristo et al. 2018), and to assess the environmental safety (Hellou 2011). A rapid assessment of the environmental effects of pollutants in water is required to protect and/or restore the health of aquatic ecosystems (Hellou 2011).

Studies on how early and sensitive responses to sub-lethal stressors are linked, such as those that occur at sub-individual levels and responses provided at different higher biological levels, represent an ecotoxicological challenge (Vighi and Villa 2009). Several studies have linked biomarker responses to behavioural alterations in aquatic organisms, including invertebrates, induced by contaminants (Peakall et al. 2002; Sandahl et al. 2005; Almeida et al. 2010; Duquesne and Kuster 2010); however, none of these studies focused on chironomids. Only data on oxidative stress responses are available for Chironomus spp. (e.g. Callaghan et al. 2001; Rodrigues et al. 2015a, 2015b). Furthermore, some studies have demonstrated the occurrence of behavioural changes produced by sub-lethal concentrations of $\mathrm{CPF}$, even at concentrations far higher than those tested in the current work (e.g. in Diamesa spp. by Villa et al. 2018a).

Thus, the current study aimed to assess the emerging hazard of pesticide contamination on the biodiversity of high mountain headwaters, by integrating responses at two levels of biological organisation. This study represents a preliminary effort to combine organismal behaviour and sub-organismal responses to CPF in alpine macroinvertebrates. Specifically, we aimed to (i) implement knowledge on the behavioural responses (BRs) of D. zernyi to sub-lethal CPF concentrations, quantifying the effect on behavioural endpoints (distance moved and speed), (ii) estimate the lower acute effect concentration of CPF and (iii) evaluate the co-occurrence of oxidative stress (OS) at tested concentrations to assess BR quantified as lipid peroxidation and protein carbonylation.

The expected effects of pesticide exposure at low levels of biological organisation might have implications for population dynamics and river food webs, still little investigated.

\section{Material and methods}

\section{Test species}

IV-instar larvae of D. zernyi were selected as the test organisms to perform behavioural and oxidative stress tests. Larvae 
were collected from the Rio Presena (altitude of $2685 \mathrm{~m}$ asl), 20-m downstream of the glacier snout (N 46' 13.5960, E 010' 34.9290) (Noce River catchment, Trentino Province, NE Italy), by using a $30 \times 30-\mathrm{cm}$ pond net (mesh size $250 \mu \mathrm{m}$ ) (Scubla SNC, Udine, Italy). Sampling was performed on two occasions in the late summer of 2017 (12, 14 and 18 September 2017) and 2018 (18 and 20 September 2018). Species were sorted in the field using tweezers. The selected larvae were placed in plastic bottles containing water from the stream and were subsequently transferred to the laboratory in cooling bags. According to Rossaro and Lencioni (2015), species were confirmed within $24 \mathrm{~h}$ of sampling using a stereomicroscope (MZ 7.5; Leica Microsystems, Germany; $\times 50$ ). In the laboratory, larvae were reared in a thermostatic chamber (ISCO, model FTD250-plus; Teledyne Isco Inc., Lincoln, NE, USA) at a controlled temperature of $2{ }^{\circ} \mathrm{C}$, which was similar to that measured in the stream water of the sampling site by using a Hydrolab Quanta (Hydrolab Corporation $®$, TX, USA) multiparametric probe. To keep the dissolved oxygen above $80 \%$ saturation, the $1-\mathrm{L}$ glass aquarium containing larvae was aerated. To allow acclimatisation to exposure conditions, IVinstar larvae were randomly selected and transferred to a 500-mL beaker (approximately 40 larvae per beaker) $24 \mathrm{~h}$ before each experiment. The $500-\mathrm{mL}$ beaker contained 200 $\mathrm{mL}$ soft-medium reconstituted water (RW) composed of 4.36 $\mathrm{mg} / \mathrm{L} \mathrm{NaHCO}_{3}, 2.73 \mathrm{mg} / \mathrm{L} \mathrm{CaSO}_{4} \cdot 2 \mathrm{H}_{2} \mathrm{O}, 2.73 \mathrm{mg} / \mathrm{L} \mathrm{MgSO} 4$ and $0.19 \mathrm{mg} / \mathrm{L} \mathrm{KCl}(\mathrm{pH}=7.7)$, following Lencioni et al. (2016). During the acclimatisation and exposure periods, larvae were not fed and were kept at $2 \pm 0.1{ }^{\circ} \mathrm{C}$ with aeration.

\section{Chemical and experimental setup of the tests}

Stock solution of chlorpyrifos (CPF) (O,O-diethyl O-3,5,6trichloro-2-pyridyl phosphorothioate) (CAS No.: 2921-88-2, purity $>95 \%$; Sigma-Aldrich, Milan, Italy) was prepared in RW and ethanol (analytical purity) to allow chemical solubilisation, and was stored at $4{ }^{\circ} \mathrm{C}$ until use. Serial dilutions in RW were performed to obtain the final test concentrations (see the "Design of the behavioural" and "Test for oxidative stress" sections for details). In the final test samples, the maximum percentage of co-solvent used was $5.2 \mathrm{E}-04 \%$ in volume $(\mathrm{v} / \mathrm{v} \%)$. This percentage was well below to the level suggested by the OECD (2000) guidelines. Negative controls (CTRL reconstructed water plus ethanol) were used in all experimental replicates. The organisms were not fed during the experiments. The stability of CPF in water was tested by adding $524 \mathrm{ng} \mathrm{L}^{-1}$ of CPF, which corresponded to the $1 / 10$ of the $\mathrm{LC}_{50}$ measured in D. zernyi by Lencioni et al. (2018). At the beginning of the test, CPF concentrations were $524 \pm$ $35 \mathrm{ng} \mathrm{L}^{-1}$. After $72 \mathrm{~h}, \mathrm{CPF}$ concentrations were $530 \pm 25 \mathrm{ng}$ $\mathrm{L}^{-1}$; thus, no degradation occurred during the test. Full details on the chemical analysis are provided by previous studies (Ferrario et al. 2017; Rizzi et al. 2019). A thermostatic chamber with a controlled temperature of $2.0 \pm 0.1{ }^{\circ} \mathrm{C}$ was used in the control and experimental exposure of larvae for 72 h. After 48-h exposure, no mortality in the control groups was observed, but ranged from 0 to $11 \%$ in the treated groups. With increased exposure time (until $72 \mathrm{~h}$ ), mortality in the control groups remained at $0 \%$, while a mean of $17 \%$ was obtained in the treatment groups. The observed values of mortality were within the acceptable range described in the European Guidelines for the Acute Immobilisation Test on Chironomus sp., (OECD 2010).

\section{Design of the behavioural}

To perform the behavioural test, the larvae were exposed for $72 \mathrm{~h}$ to $1.1 \mathrm{ng} \mathrm{L}^{-1} ; 5.24 \mathrm{ng} \mathrm{L}^{-1} ; 11.0 \mathrm{ng} \mathrm{L}^{-1} ; 52.4 \mathrm{ng} \mathrm{L}^{-1}$; $110 \mathrm{ng} \mathrm{L}^{-1} ; 262 \mathrm{ng} \mathrm{L}^{-1} ; 524 \mathrm{ng} \mathrm{L}^{-1}$ and $1100 \mathrm{ng} \mathrm{L}^{-1}$ of the insecticide (the behavioural response at $1100 \mathrm{ng} \mathrm{L}^{-1}$ was published in Villa et al. 2018a). In brief, the selected test concentrations were obtained from serial dilutions, starting from $\mathrm{LC}_{50}$ and $\mathrm{LC}_{10}$ values of the chemical, before measuring them for this organism $\left(5.24 \mu \mathrm{g} \mathrm{L}^{-1}\right.$ and $1.1 \mu \mathrm{g} \mathrm{L}^{-1}$, respectively; Lencioni et al. 2018). In particular, the AA-EQS (Annual Average-Environmental Quality Standard) value of $0.03 \mu \mathrm{g}$ $\mathrm{L}^{-1}$ given in the Directive 2008/105/EC for priority substances and other pollutants was identified to choose the test concentrations; thus, three values below and four values above the EQS were used.

The obtained concentrations were environmentally relevant and were very close to those recently measured in the surface freshwater streams of Alpine environments in Italy. In particular, in the Rio Presena, where the larvae were collected, a concentration of CPF ranging from 9.43 to $13.0 \mathrm{ng} \mathrm{L}^{-1}$ was recorded during the summer season of 2016 (Rizzi et al. 2019).

\section{Video footage and swimming parameter analysis}

After 72-h exposure, $180 \mathrm{~s}$ of video footage was taken using a digital high-definition camera (Raspberry Pi 3 with Camera Module v2) at high resolution (1920-1080 pixels), which was positioned at $10 \mathrm{~cm}$ from the bottom of the beaker. FFmpeg software (http://www.ffmpeg.org) was used to convert each video to an .avi file that was subsequently partitioned to five sections of video of $30 \mathrm{~s}$ each ( 900 frames; 30 frames s ${ }^{-1}$ ). The obtained sections were analysed using the software ImageJ (http://imagej.nih.gov/ij/), to quantify the "total distance moved" (mm) and the "average speed" $\left(\mathrm{mm} \mathrm{s}^{-1}\right)$ of $D$. zernyi larvae. The parameters of ImageJ software were optimised according the description provided by Villa et al. (2018a). As described in Villa et al. (2018b), the data obtained for the two endpoints were converted from pixels to millimetres (distance) and from pixels per second to millimetres per second (speed). The sum of the distances travelled by the larvae 
from the start to the finish of each video corresponded to the "total distance moved". In comparison, the speed of movement obtained frame by frame as the ratio length/time $\left(\mathrm{mm} \mathrm{s}^{-}\right.$ ${ }^{1}$ ) corresponded to the "average speed". The length means the total of the lengths of all vectors of movement between frames given track.

\section{Test for oxidative stress}

The concentrations were selected based on the results of the behavioural analysis, and the fact that the test organisms originated from a natural population in the wild; thus, the number of larvae was limited. Consequently, the oxidative stress of D. zernyi was assessed at $110 \mathrm{ng} \mathrm{L}^{-1}, 524 \mathrm{ng} \mathrm{L}^{-1}$ and $1110 \mathrm{ng} \mathrm{L}^{-1} \mathrm{CPF}$. Three independent experiments were developed for each set of conditions in which 80 larvae were used. The larvae were frozen and stored at $-80{ }^{\circ} \mathrm{C}$ for lipid and protein extraction.

\section{Preparation of the homogenate}

Pooled samples of 80 larvae were homogenised with $300 \mu \mathrm{L}$ MDA buffer (ab118970; Sigma-Aldrich, Milano, Italy) and 3 $\mu \mathrm{L}$ butylated hydroxy-ethylene (BHT) 100X (ab126287, Sigma-Aldrich, Milano Italy), to avoid the artificial lipid peroxidation during the assay. The homogenate was centrifuged at $13,000 \mathrm{~g}$ for $10 \mathrm{~min}$ at $4{ }^{\circ} \mathrm{C}$. Then, the supernatant was collected in an Eppendorf tube for protein, MDA and protein carbonyl content (PCC) quantification.

\section{Quantification of proteins}

The amount of proteins was quantified following the Bradford Method (Bradford 1976). A calibration curve was generated using known concentrations of Bovine Serum Albumin (BSA). A $10-\mu \mathrm{L}$ volume of the standards or sample was mixed with $200 \mu \mathrm{L}$ Bradford reactive (B6916; SigmaAldrich, Milano, Italy), and maintained for $15 \mathrm{~min}$ at room temperature. The solution was finally measured at $595 \mathrm{~nm}$ (LAMBDA XLS/XLS+ Spectrophotometer, PerkinElmer).

\section{Lipid peroxidation MDA analysis}

The reaction between the MDA present in the sample and thiobarbituric acid (TBA) generates a compound that is easily quantified by spectrophotometry (absorbance at $532 \mathrm{~nm}$ ). MDA was quantified using the lipid peroxidation (MDA) assay kit (colorimetric/fluorometric) (Abcam) following the manufacturer's protocol. This assay allowed MDA content in the homogenate sample to be quantified. To calculate the nanomoles of MDA in the samples, a calibration curve was constructed using standards with a known concentration of
MDA ( 1 to $20 \mathrm{nmol}$ ). The final result was expressed as nanomol (nmol) MDA per milligramme of protein.

\section{Protein carbonyl analysis}

Levine et al. (1990) generated a spectrophotometric quantification (absorption wavelength $=375 \mathrm{~nm}$ ) that allows the reaction products (hydrazones) of dinitrophenylhydrazine (DNPH) to be evaluated using the carbonyl groups of proteins. PCC was quantified using the carbon protein content assay kit (Abcam) according to the manufacturer's protocol. The final result was expressed as nmol protein carbonyl per milligramme of total protein $(\mathrm{CP})$. The calculations were completed according to the Eqs. 1 and 2. Equation 1 was developed to calculate the amount of carbonylated proteins in the sample (nmol), while Eq. 2 was developed to calculate the total amount of carbonyls in the protein sample $\left(\mathrm{nmol} \mathrm{mg}^{-1}\right)$.

$$
\begin{aligned}
& C=\left(\frac{\mathrm{Abs}}{\varepsilon}\right) \times 100 \\
& \mathrm{CP}=\frac{C}{P}
\end{aligned}
$$

where $C$ is the amount of carbonyl in the sample (nmol/bucket); Abs is the absorption wavelength at $375 \mathrm{~nm}$; $\varepsilon$ equals 0.22 , which is the molar extinction coefficient for the bucket used expressed as nMCP (nmol carbonyl per mg protein) and $P$ is the milligrammes of proteins in the sample, which was calculated from the standard curve of the Bradford method

\section{Statistical analysis}

Before analysing the data, the presence of outliers was investigated using the ROUT (robust regression and outlier removal) method. Statistical significance of behavioural and biochemical changes under chemical stress was investigated using GraphPad Prism 6 software (version 6.01; 2012) and SPSS 24 software (IBM). One-way analysis of variance (ANOVA) was used when the hypothesis of normality and homoscedasticity was met (D'Agostino and Pearson omnibus normality test; Shapiro-Wilk normality test; Levene test). The results of each treatment group were compared with the control group and treatment level differences using Dunnett's, Tukey's, and Games-Howell's post hoc tests (multiple comparisons). Non-parametric tests were used (Dunn's multiple post hoc comparisons test) when the data did not follow a normal distribution. 


\section{Results}

\section{Behavioural responses}

The behavioural responses were expressed as total distance moved and average speed, and were quantified after 72-h exposure to CPF (Fig. 1). All measured data, including the results of the statistical analyses, are presented in the Supporting Information section (Table SI 1-3). To obtain an overview of the BR profile of $D$. zernyi exposed to varying $\mathrm{CPF}$ concentrations, we included the results of CPF $1100 \mathrm{ng} \mathrm{L}^{-1}$ exposure from a previous study by our group in Fig. 1 (Villa et al. 2018a).

A concentration threshold effect was observed in the responses of larvae exposed to concentrations above and below a threshold of 52.4 and $110 \mathrm{ng} \mathrm{L}^{-1}$ (Tables S2; S3). D. zernyi larvae exposed to concentrations $\leq 52.4 \mathrm{ng} \mathrm{L}^{-1}$ showed no statistically significant differences in the swimming distance of larvae in the treated groups compared with the controls (Fig. 1a; mean range 5.7-8.4 mm for treatment groups versus $4.9 \mathrm{~mm}$ for the control). Compared with the control, at a concentration $\geq 110 \mathrm{ng} \mathrm{L}^{-1}$, the swimming distance of larvae significantly declined $(p<0.0001$ for groups treated at 110 and $262 \mathrm{ng} \mathrm{L}^{-1}, p<0.05$ at $524 \mathrm{ng} \mathrm{L}^{-1}$ and $p<0.01$ at $1100 \mathrm{ng}$ $\left.\mathrm{L}^{-1}\right)$. No statistically significant difference was observed among treated larvae groups. The mean value of the distance travelled in the treated groups ranged from 0.6 to $1.5 \mathrm{~mm}$ (4.9 $\mathrm{mm}$ in the control). Swimming speed showed a similar trend to the threshold effect for concentrations between 52.4 and $110 \mathrm{ng} \mathrm{L}^{-1}$ (Fig. 1b; Table S3). For swimming distance, no significant difference was detected with the control (mean $0.8 \mathrm{~mm} \mathrm{~s}^{-1}$ ) or among groups exposed to concentrations of up to $52.4 \mathrm{ng} \mathrm{L}^{-1}$, with mean recorded values ranging from 0.6 to $1.0 \mathrm{~mm} \mathrm{~s}^{-1}$. At concentrations $\geq 110 \mathrm{ng} \mathrm{L}^{-1}$, only larvae exposed to 110 and $262 \mathrm{ng} \mathrm{L}^{-1}$ significantly reduced swimming speed ( $p<0.0001$; mean 0.23 and $0.20 \mathrm{~mm} \mathrm{~s}^{-1}$, respectively).

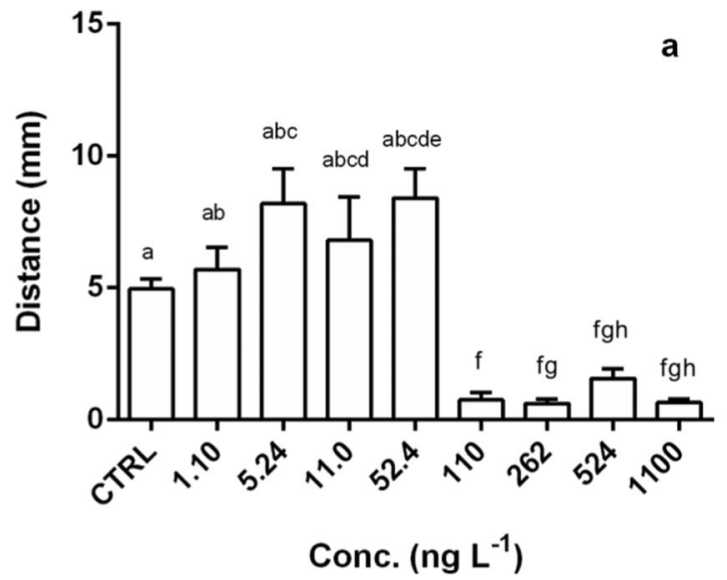

Fig. 1 Histograms of BR (distance travelled [a] and average speed [b]) (means $\pm \mathrm{SD}$ of three replicates for each measurement) of Diamesa zernyi larvae exposed for $72 \mathrm{~h}$ to increasing concentrations $\left(\mathrm{ng} \mathrm{L}^{-1}\right)$ of chlorpyrifos. Significant differences between treated groups and the
In comparison, the mean speed recorded at the highest concentrations was similar to the control $\left(0.68 \mathrm{~mm} \mathrm{~s}^{-1}\right.$, and $0.4 \mathrm{~mm} \mathrm{~s}^{-1}$, based on data from Villa et al. 2018a).

\section{Oxidative stress responses}

\section{MDA and PCC analyses}

The MDA and PCC analyses are presented in Fig. 2. After 72 $\mathrm{h}$, exposure to $\mathrm{CPF}$ generated strong oxidative stress on D. zernyi larvae at all the tested concentrations (all measured data and the statistical results are presented in Table SI 4-6).

For lipid peroxidation, a statistically significant increase in MDA levels with respect to the control was detected for all the tested concentrations $\left(p<0.05\right.$ at $110 \mathrm{ng} \mathrm{L}^{-1}$ and $p<0.01$ at 524 and $1100 \mathrm{ng} \mathrm{L}^{-1}$ ) (Fig. 2a). Significant differences were also recorded for all treatments ( $p$ value $<0.01$ and 0.001 ). Similar results were obtained for PCC content (Fig. 2b). Compared with the control, a high and significantly different carbonyl content was obtained for all treated groups $\left(p<0.01\right.$ at $110 \mathrm{ng} \mathrm{L}^{-1}$ and $1100 \mathrm{ng} \mathrm{L}^{-1}$ and $p<0.001$ at $\left.524 \mathrm{ng} \mathrm{L}^{-1}\right)$. Again, a significant difference was obtained among all treatments $(p<0.01)$.

A similar response was provided by both endpoints (lipid peroxidation and protein carbonylation). However, a higher decrease between 524 and $1100 \mathrm{ng} \mathrm{L}^{-1}$ exposure was observed for MDA levels.

\section{Discussion}

\section{Cellular stress and behavioural responses}

The current study demonstrated that the exposure to sub-lethal concentrations of CPF (> $52 \mathrm{ng} \mathrm{L}^{-1}$ ) provoked a marked alteration to the oxidative status of $D$. zernyi larvae, and strongly

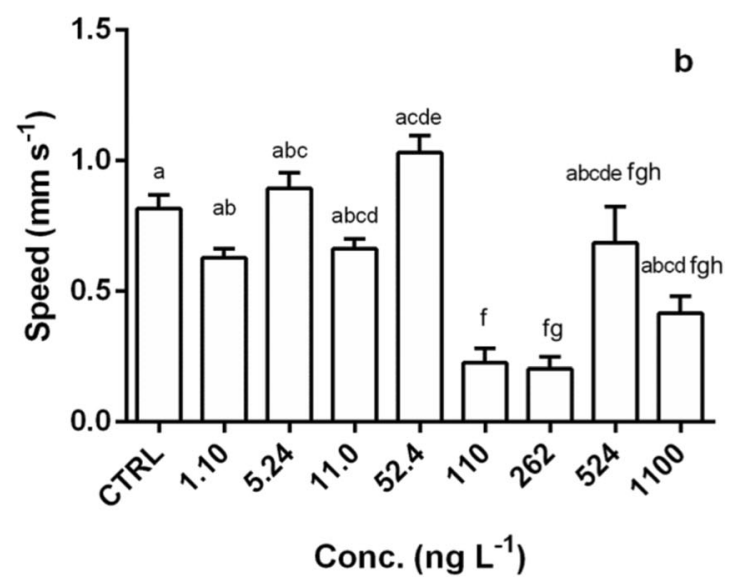

control, as well as among groups, are indicated with different capital and lowercase letters. Figure is created with GraphPad Prism 6 Program (version 6.01) and is in TIFF format. Resolution used was of $1200 \mathrm{dpi}$ 


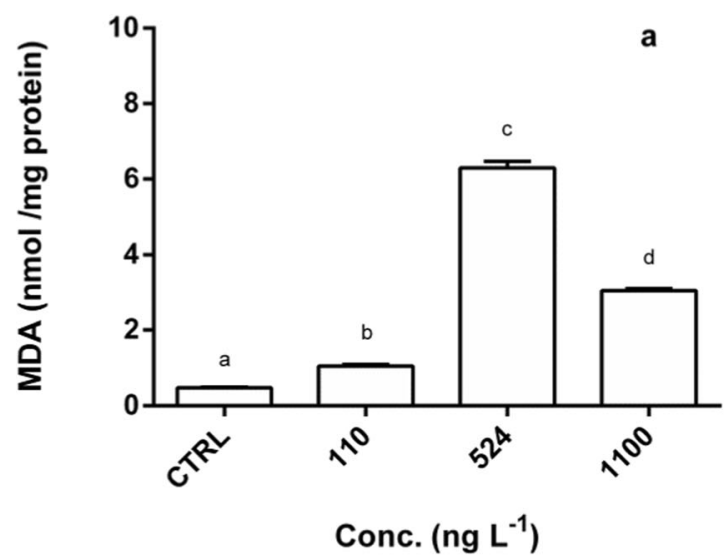

Fig. 2 MDA levels [a] and PCC content $[\mathbf{b}]$ (means \pm SD of three replicates for each measurement) of Diamesa zernyi larvae exposed for $72 \mathrm{~h}$ to increasing concentrations of chlorpyrifos. Significant differences between treated groups and the control, as well as among treatments, are

inhibited their locomotor ability. Significant ROS overproduction was detected through the analysis of MDA and PCC content, and was correlated with swimming behaviour parameters. In fact, at CPF concentrations where the mobility of the larvae was strongly inhibited, a significant level of oxidative damage was observed, with lipid peroxidation and protein carbonylation processes increasing. This increase in oxidative damage might reduce the locomotor performance of organisms, similar to that documented for tested environmental concentrations of CPF on the larvae of the damselfly Enallagma cyathigerum (Janssens and Stoks 2017).

Increased ROS production in aquatic organisms exposed to CPF has been demonstrated by several studies (Gupta et al. 2010; Sharbidre et al. 2011; Patetsini et al. 2013; Cacciatore et al. 2015; Jin et al. 2015; Bertrand et al. 2016; Janssens and Stoks 2017), with different processes possibly explaining this phenomenon. First, CPF is an organophosphorus compound that exerts its toxicity by inhibiting the enzyme acetylcholinesterase (AChE), which is responsible for free radical production (Lushchak 2011). In addition, the superoxide anion released as a by-product of AChE inhibition might provoke damage of the superoxide dismutase (SOD) enzyme (Cacciatore et al. 2015), which plays an important role in oxidative damage protection processes. Previous studies showed that in the presence of CPF, SOD and catalase (CAT) antioxidant enzymes and other parts of the antioxidant system were reduced by the lowered glutathione peroxidase (GPx) and glutathione-S-transferase (GST) (Cacciatore et al. 2015; Jin et al. 2015; Janssens and Stoks 2017; Ferrario et al. 2018). The formulated hypothesis stated that antioxidant defences are lowered because available energy is mainly employed to detoxify and repair cells (Patetsini et al. 2013; Cacciatore et al. 2015). The correlation between antioxidant and detoxifying enzymes and behavioural impairments in Daphnia magna was highlighted by Ferrario et al. (2018). Ferrario et al. (2018) explained that changes to behaviour

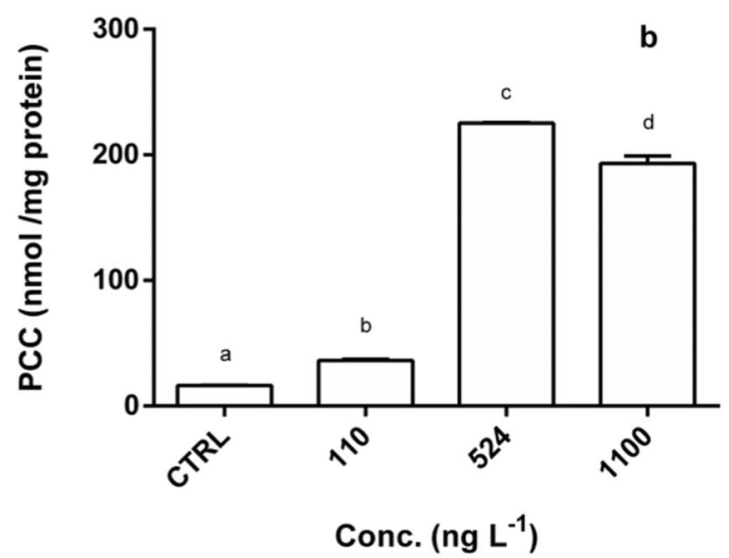

indicated with different letters. Figure is created with GraphPad Prism 6 Program (version 6.01) and is in TIFF format. Resolution used was of $1200 \mathrm{dpi}$

occurred as a function of the activation or non-activation of antioxidant and detoxifying enzyme activities. A similar strategy might have been used by the larvae in our study to counteract ongoing stress leading to increased ROS production.

We did not evaluate the enzymatic activity involved in detoxification processes; however, at higher levels of CPF, enzymatic activity might be activated, as indicated by the significant decrease in MDA and PCC content (e.g. at $1100 \mathrm{ng} \mathrm{L}^{-1}$ ). This phenomenon might have been how cells attempted to discharge damaged proteins, as shown by previous studies (Monaghan et al. 2009; Rodríguez-Seijo et al. 2018). For instance, Rodríguez-Seijo et al. (2018) evaluated lipid peroxidation in Lumbricidae (Eisenia fetida) and noted a decrease in the expression of thiobarbituric acid reactive substances (TBARS), of which MDA was one, at the highest tested concentration of toxicity. The authors found that low MDA levels were correlated with increased CAT and GST enzyme levels as defence mechanisms, counteracting the effects of ROS species and, thus, decreasing oxidative damage. Also, for PCC content, a decrease in the highest CPF concentration was recorded, supporting the results of previous authors that tested the environmental concentrations of this insecticide on Palaemonetes argentinus for $96 \mathrm{~h}$ (Bertrand et al. 2016). This trend could be explained by an increase in the rate of protein turnover, due to oxidative stress that usually reduces protein concentrations (Narra et al. 2013).

\section{Interpretation of the behavioural trends of Diamesa zernyi larvae under increasing chemical stress}

A threshold effect of the BRs was detected at concentrations ranging between 52.4 and $110 \mathrm{ng} \mathrm{L}^{-1}$. Our findings support those of previous studies showing a concentration- dependent trend of BR consistent with the Stepwise Stress Model (SSM) of aquatic organisms exposed to different toxicants, including organophosphate insecticides (Ren et al. 2007, 2009, 2012). 
The SSM postulates the existence of a sequence of changes to BR produced by organisms exposed to an increasing stress stimulus (in terms of both concentration and time) (no effect, stimulation, acclimation, adjustment [readjustment] and toxic effect) that are compensatory to the ongoing stress condition (Gerhardt 1999; Gerhardt et al. 2005).

With the persistence of a given stimulus level, the organism could acclimatise to the new conditions and changes its behaviour (acclimation phase), reducing its BR performance to enhance another process (Ren et al. 2007). For instance, in an attempt to repair damage from oxidative stress and maintain standard metabolism, an organism could activate certain defence mechanisms (e.g. antioxidant and detoxification processes) that reallocate energy used for other functions (i.e. maintaining activity), including the ability to move normally. This condition cannot be sustained for a long time, eventually compromising locomotion ability (resistance threshold of the organism) (Ren et al. 2009).

In addition, after a phase in which effects are not observed (no effect), a stimulation phase of the BR (described as the avoidance behaviour of the organism) is produced. In our study, at low concentrations (from 1.1 to $52.4 \mathrm{ng} \mathrm{L}^{-1}$ ), statistically significant changes to the distance moved and the speed of the movement with respect to untreated organisms were not detected, even when both parameters increased. After the no effect phase, a rapid decay in larval mobility was observed at $110 \mathrm{ng} \mathrm{\textrm {L } ^ { - 1 }}$. Presumably, the gradual weakening of mobility corresponding to the acclimation phase might be intercepted at concentrations of 52.4 to $110 \mathrm{ng} \mathrm{L}^{-1}$. The concentration of $110 \mathrm{ng} \mathrm{L}^{-1}$ seemed to correspond to the resistance threshold of organisms that could no longer sustain a continuous state of alarm, with mobility being lost after $72 \mathrm{~h}$. To behave normally, organisms need energy, with the presence of sub-lethal chemical stress conditions possibly forcing them to activate compensatory mechanisms that are energetically expensive. In our study, after 72-h exposure to concentrations $\geq$ $110 \mathrm{ng} \mathrm{L}^{-1} \mathrm{CPF}$, the energy usually employed for normal swimming activity might have been reallocated to cope with toxic stress (De Coen and Janssen 2003). The equilibrium in energy allocation among the different components of the energy budget of an organism is essential to sustain life, growth and reproduction, with changes potentially having important consequences on the fitness of the population (Monaghan et al. 2009).

The locomotor performance of a species is an ecologically relevant trait for population dynamics (Forbes and Calow 1999), because it facilitates the survival of an organism and, ultimately, population fitness. For instance, locomotor performance is directly related to the ability of an organism to escape from predators and, hence, to population growth rates. Consequently, sub-lethal effects provoked by environmental concentrations of pesticides could have long-term impacts on populations and, even, communities (Amiard-Triquet 2009; Duquesne and Kuster 2010).

\section{Potential threat for aquatic ecosystems}

The impairment of the behavioural activities of $D$. zernyi larvae was induced at concentrations very near to those measured in high mountain aquatic ecosystems inhabited by $D$. zernyi. For instance, $\mathrm{CPF}$ concentrations ranging from 2 to $70 \mathrm{ng} \mathrm{L}^{-1}$ were detected in the glacial melt water of six Alpine glaciers during the ablation season of 2016 (Rizzi et al. 2019). Furthermore, concentrations of about $200 \mathrm{ng} \mathrm{L}^{-1}$ (up to $500 \mathrm{ng} \mathrm{L}^{-1}$ ) of this pesticide were detected at lower altitudes $(<1100 \mathrm{~m}$ asl $)$ in the alpine river Rio Novella in 2011 and 2012 (Morselli et al. 2018). Based on the detection levels of this pesticide in the natural environment and our study results, the threat to mountain aquatic species must be acknowledged, along with the combined effect of multiple stressors on aquatic ecosystems, such as the repeated exposure of pesticide mixtures in combination with global warming.

\section{Conclusions}

This study confirmed the detrimental effects of environmental concentrations of chlorpyrifos on D. zernyi larvae. In particular, the concentrations at which the insecticide was found in high mountain streams significantly inhibited the swimming activity of this organism. The locomotor capability of $D$. zernyi might be reduced due to the organism reallocating energetic reserves to combat strong oxidative stress. The behavioural changes detected in this study might propagate long-term changes to both population and community levels, presenting a realistic ecological risk for Alpine aquatic ecosystems where pesticides cannot be excluded.

Acknowledgements We thank Alessandra Franceschini, Francesca Paoli and Francesco Bellamoli (MUSE-Museo delle Scienze of Trento) for helping with field and laboratory work.

Funding information This work was supported by the Cassa di Risparmio di Trento e Rovereto Foundation (CARITRO No. Rif. Int.: 2015.0199; 2015-2018) within the RACE-TN Project ("Valutazione del rischio ambientale dei contaminanti emergenti nei fiumi trentini: effetti sulla vita selvatica e sull'uomo"/"Environmental Risk assessment of emerging contaminants in Trentino rivers: effects on wildlife and human health", Grant No. 2015.0199; 2015-2018) coordinated by Valeria Lencioni (MUSE), by the MUSE and by the University of MilanoBicocca.

\section{Compliance with ethical standards}

Conflict of interest The authors declare that there are no conflicts of interest. 


\section{References}

Almeida JR, Oliveira C, Gravato C, Guilhermino L (2010) Linking behavioural alterations with biomarkers responses in the European seabass Dicentrarchus labrax 1. exposed to the organophosphate pesticide fenitrothion. Ecotoxicology 19:1369-1381

Amiard-Triquet C (2009) Behavioral disturbances: the missing link between suborganismal and supra-organismal responses to stress? Prospects based on Aquatic Research. Hum Ecol Risk Assess 15: $87-110$

Bertrand L, Monferrán MV, Mouneyrac C, Bonansea RI, Asis R, Amé MV (2016) Sensitive biomarker responses of the shrimp Palaemonetes argentines exposed to chlorpyrifos at environmental concentrations: roles of alpha-tocopherol and metallothioneins. Aquat Toxicol 179:72-81. https://doi.org/10.1016/j.aquatox.2016. 08.014

Betteridge DJ (2000) What is oxidative stress? Metabolism 49:3-8. https://doi.org/10.1016/S0026-0495(00)80077-3

Bradford M (1976) A rapid and sensitive method for the quantitation of microgram quantities of protein utilizing the principle of protein-dye binding. Anal Biochem 72:248-254. https://doi.org/10.1016/00032697(76) $90527-3$

Cacciatore LC, Nemirovsky SI, Verrengia Guerrero NR, Cochón AC (2015) Azinphos-methyl and chlorpyrifos, alone or in a binary mixture, produce oxidative stress and lipid peroxidation in the freshwater gastropod Planorbarius corneus. Aquat Toxicol 167:12-19

Callaghan A, Hirthe G, Fisher T, Crane M (2001) Effect of short-term exposure to chlorpyrifos on developmental parameters and biochemical biomarkers in Chironomus riparius Meigen. Ecotoxicol Environ Saf 50:19-24. https://doi.org/10.1006/eesa.2001.2071

Darko G, Akoto O, Oppong C (2008) Persistent organochlorine pesticide residues in fish, sediments and water from Lake Bosomtwi, Ghana. Chemosphere 72:21-24

De Coen WM, Janssen CR (2003) A multivariate biomarker-based model predicting population-level responses of Daphnia magna. Environ Toxicol Chem 22:2195-2201

Dell'Omo G (2002) Behavioural ecotoxicology. John Wiley \& Sons, Chichester

Duquesne S (2006) Effects of an organophosphate on Daphnia magna at suborganismal and organismal levels: implications for population dynamics. Ecotoxicol Environ Saf 65:145-150

Duquesne S, Kuster E (2010) Biochemical metabolic and behavioural responses and recovery of Daphnia magna after exposure to an organophosphate. Ecotoxicol Environ Saf 73:353-359

Ferrario C, Finizio A, Villa S (2017) Legacy and emerging contaminants in meltwater of three alpine glaciers. Sci Total Environ 574:350-357

Ferrario C, Parolini M, De Felice B, Villa S, Finizio A (2018) Linking sub-individual and supra-individual effects in Daphnia magna exposed to sub-lethal concentration of chlorpyrifos. Environ Pollut 235:411-418. https://doi.org/10.1016/j.envpol.2017.12.113

Forbes VE, Calow P (1999) Is the per capita rate of increase a good measure of population-level effects in ecotoxicology? Environ Toxicol Chem 18:1544-1556

Forbes VE, Palmqvist A, Bach L (2006) The use and misuse of biomarkers in ecotoxicology. Environ Toxicol Chem 25:272-280

Gerhardt A (ed) (1999) Biomonitoring of polluted water. Reviews on Actual Topics. Environmental Research Forum 9. TransTech Publishers, Zürich

Gerhardt A, Janssens de Bisthoven L, Soares AM (2005) Evidence for the Stepwise Stress Model: Gambusia holbrooki and Daphnia magna under acid mine drainage and acidified reference water stress. Environ Sci Technol 39:4150-4158

Gerhardt A (2007) Aquatic behavioral ecotoxicology prospects and limitations. Hum Ecol Risk Assess Int J 13:481-491
Guida YS, Meire RO, Machado JP, Malm TO (2018) Air contamination by legacy and current-use pesticides in Brazilian mountains: an overview of national regulations by monitoring pollutant presence in pristine areas. Environ Pollut 242(Part A):19-30

Gupta SC, Mishra M, Sharma A, Balaji TGRD, Kumar R, Mishra RK, Chowdhuri DK (2010) Chlorpyrifos induces apoptosis and DNA damage in Drosophila through generation of reactive oxygen species. Ecotoxicol Environ Saf 73:1415-1423

Janssens L, Stoks R (2017) Chlorpyrifos-induced oxidative damage is reduced under warming and predation risk: explaining antagonistic interactions with a pesticide. Environ Pollut 226:79-88

Jin Y, Liu Z, Peng T, Fu Z (2015) The toxicity of chlorpyrifos on the early life stage of zebrafish: a survey on the endpoints at development, locomotor behavior, oxidative stress and immunotoxicity. Fish Shellfish Immun 43:405-414

Hellou J (2011) Behavioural ecotoxicology, an "early warning” signal to assess environmental quality. Environ Sci Pollut Res 18:1-11

Lencioni V, Grazioli V, Rossaro B, Bernabo P (2016) Gene expression profiling of responses induced by pesticides employed in organic agriculture in a wild population of the midge Chironomus riparius. Sci Total Environ 557-558:183-191

Lencioni V, Rossaro B (2005) Microdistribution of chironomids (Diptera: Chironomidae) in Alpine streams: an auto-ecological perspective. Hydrobiologia 533:61-76

Lencioni V (2018) Glacial influence and macroinvertebrate biodiversity under climate change: lessons from the Southern Alps. Sci Total Environ 622-623:563-575

Lencioni V, Bellamoli F, Bernabò P, Miari F, Scotti A (2018) Response of Diamesa spp. (Diptera: Chironomidae) from Alpine streams to emerging contaminants and pesticides. J Limnol 77(s1):131-140

Levine RL, Garland D, Oliver CN, Amici A, Climent I, Lenz AG, Ahn BW, Shaltiel S, Stadtman ER (1990) Determination of carbonyl content in oxidatively modified proteins. Methods Enzymol 186: 464-478

Liu Y, Li S, Ni Z, Qu M, Zhong D, Ye C, Tang F (2016) Pesticides in persimmons, jujubes and soil from China: residue levels, risk assessment and relationship between fruits and soils. Sci Total Environ 542:620-628

Liu J, Schelar E (2012) Pesticide exposure and child neurodevelopment: summary and implications. Workplace Health Saf 60:243

Lushchak VI (2011) Environmentally induced oxidative stress in aquatic animals. Aquat Toxicol 101:13-30

Monaghan P, Metcalfe NB, Torres R (2009) Oxidative stress as a mediator of life history trade-offs: mechanisms, measurements and interpretation. Ecol Lett 12:75-92

Morselli M, Vitale CM, Ippolito A, Villa S, Giacchini R, Vighi M, Di Guardo A (2018) Predicting pesticide fate in small cultivated mountain watersheds using the integrated DynAPlus model: towards improved assessment of peak exposure. Sci Total Environ 615:307-318

Narra MR, Regatte RR, Kodimyala R (2013) J Stress Physiol Biochem 9: 219-231 ISSN 1997-0838

OECD (2000) OECD guidelines for testing of chemicals Sediment-Water Chironomid Life-Cycle Toxicity Test Using Spiked Water or Spiked Sediment. OECD Publishing, Paris

OECD (2010) OECD Guideline for Testing Of Chemicals. Chironomus sp., Acute Immobilisation Test. 8 October 2010

Patetsini E, Dimitriadis VK, Kaloyianni M (2013) Biomarkers in marine mussels, Mytilus galloprovincialis, exposed to environmentally relevant levels of the pesticides, chlorpyrifos and penoxsulam. Aquat Toxicol 126:338-345

Peakall DB, Thompson H, Baatrup E (2002) Relationship between behaviour and the biochemical/physiological biomarkers of exposure to environmental pollutants. In: Dell'Omo G (ed) Behavioural Ecotoxicology. Wiley, Chichester, pp 187-208

Ren Z, Zha J, Ma M, Wang Z, Gerhardt A (2007) The early warning of aquatic organophosphorus pesticide contamination by on-line 
monitoring behavioral changes of Daphnia magna. Environ Monit Assess 134:373-383

Ren ZM, Li ZL, Zha JM, Kf R, Ma M, Wang Z, Fu RS (2009) The avoidance responses of Daphnia magna to the exposure of organophosphorus pesticides in an on-line biomonitoring system. Environ Model Assess 14:405-410

Ren ZM, Fu XE, Zeng Y, Liu YD, Kim HS, Chon TS (2012) The stepwise behavioral responses of medaka (Oryzias latipes) to organophosphorus pesticides in an online monitoring system. Procedia Environ Sci 13:1122-1133

Rizzi C, Finizio A, Maggi V, Villa S (2019) Spatial-temporal analysis and risk characterization of pesticides in Alpine glacial streams. Environ Pollut 248:659-666

Rodrigues ACM, Gravato C, Quintaneiro C, Golovko O, Žlábek V, Barata C, Soares AMVM, Pestana JLT (2015a) Life history and biochemical effects of chlorantraniliprole on Chironomus riparius. Sci Total Environ 508:506-513

Rodrigues ACM, Gravato C, Quintaneiro C, Golovko O, Žlábek V, Barata C, Soares AMVM, Soares AMVM, Pestana JLT (2015b) Sub-lethal toxicity of environmentally relevant concentrations of esfenvalerate to Chironomus riparius. Environ Pollut 207:273-279

Rodríguez-Seijo A, da Costa JP, Rocha-Santos T, Duarte AC, Pereira R (2018) Oxidative stress, energy metabolism and molecular responses of earthworms (Eisenia fetida) exposed to low-density polyethylene microplastics. Environ Sci Pollut Res 25:33599-33610. https://doi.org/10.1007/s11356-018-3317-z

Rossaro B, Lencioni V (2015) A key to larvae of species belonging to the genus Diamesa from Alps and Apennines (Italy). Eur J Environ Sci 5:62-79

Saaristo M, Brodin T, Balshine S, Bertram MG, Brooks BW, Ehlman SM, McCallum ES, Sih A, Sundin J, Wong BBM, Arnold KE (2018) Direct and indirect effects of chemical contaminants on the behaviour, ecology and evolution of wildlife. Proc R Soc B 285: 20181297. https://doi.org/10.1098/rspb.2018.1297

Sandahl J, Baldwin DH, Jenkins JJ, Scholz NL (2005) Comparative thresholds for scetylcholinesterase inhibition and bImpairment in coho salmon exposed to chlorpyrifos. Environ Toxicol Chem 24: $136-145$

Santolaria Z, Arruebo T, Pardo A, Matesanz JM, Bartolomè A, Caixach J, Lanaja FJ, Urieta JS (2015) Evaluation of airborne organic pollutants in a Pyrenean glacial Lake (the Sabocos Tarn). Water Air Soil Pollut 226:226-383

Sharbidre AA, Metkari V, Patode P (2011) Effect of methyl parathion and chlorpyrifos on certain biomarkers in various tissues of guppy fish, Poecilia reticulata. Pestic Biochem Physiol 101:132-141

Scott GR, Sloman KA (2004) The effects of environmental pollutants on complex fish behaviour: integrating behavioural and physiological indicators of toxicity. Aquat Toxicol 68:369-392. https://doi.org/10. 1016/j.aquatox.2004.03.016

Sloman KA, Mcneil PL (2012) Using physiology and behaviour to understand the responses of fish early life stages to toxicants. J Fish Biol 81:2175-2198. https://doi.org/10.1111/j.1095-8649.2012. 03435. $\mathrm{x}$

Stehle S, Schulz R (2015) Agricultural insecticides threaten surface waters at the global scale. PNAS 112:5750-5575

Sun J, Pan L, Tsang DCW, Zhan Y, Zhu L, Li X (2018) Organic contamination and remediation in the agricultural soils of China: a critical review. Sci Total Environ 615:724-740

Villa S, Di Nica V, Pescatore T, Bellamoli F, Miari F, Finizio A, Lencioni V (2018a) Comparison of the behavioural effects of pharmaceuticals and pesticides on Diamesa zernyi larvae (Chironomidae). Environ Pollut 238:130-139

Villa S, Di Nica V, Bellamoli F, Pescatore T, Ferrario C, Finizio A, Lencioni V (2018b) Effects on behaviour traits of a treated sewage effluent in Diamesa cinerella and Daphnia magna. J Limnol 77(s1). https://doi.org/10.4081/jlimnol.2018.1760

Vighi M, Villa S (2009) Ecotoxicology: the challenges for the 21st century. Toxics 1:18-35. https://doi.org/10.3390/toxics1010018

Publisher's note Springer Nature remains neutral with regard to jurisdictional claims in published maps and institutional affiliations. 